Published in final edited form as:

Science. 2003 September 19; 301(5640): 1679-1681. doi:10.1126/science.1090529.

\title{
It's Never Too Late
}

\author{
James W. Vaupel, James R. Carey, and Kaare Christensen \\ J. W. Vaupel is at the Max Planck Institute for Demographic Research, Konrad-Zuse-Strasse 1, \\ $D-18057$ Rostock, Germany.J. R. Carey is in the Department of Entomology, University of California, \\ Davis, CA 95616, USA, and the Center for the Economics and Demography of Aging, University of \\ California, Berkeley, CA 94720, USA. K. Christensen is at the Institute of Public Health, University \\ of Southern Denmark, DK-5000 Odense, Denmark
}

Experiments in species as diverse as yeast, worms, flies, and rodents demonstrate that dietary restriction prolongs survival. The encouraging findings of Mair et al. (1) on page 1731 of this issue now reveal that a lifetime of abstemiousness is not required to reduce one's risk of death -at least in fruit flies. These investigators show that when flies fed a restricted diet are switched to a full diet, mortality soars to the level suffered by fully fed flies. Conversely, when the diet of fully fed Drosophila is restricted, mortality plunges within 2 days to the level enjoyed by flies that have experienced a lifelong restricted diet.

The alliterative title of the Mair et al. paper-"Demography of Dietary Restriction and Death in Drosophila"- gives due credit to demography as the source of their new discovery. Demographers have long realized that death rates provide age-specific information that cumulative survival curves cannot (2). Heeding this insight, Mair et al. analyzed the daily mortality of their fed and hungry flies. Demography offers a further lesson: Death of the frail alters the composition of a cohort, lowering subsequent mortality and possibly offsetting increases in mortality resulting from cumulative damage (3).

Replication and refinement of Mair et al.'s experiments especially in rodents, the principal animal model of dietary-restriction studies, will be a research priority. Rodent and Drosophila dietary-restriction experiments differ in two key respects. First, rodents in these experiments cannot mate or produce offspring because they are maintained in solitary confinement or in same-sex cages. Mair et al. allowed their flies to mate before separating them into containers holding about 100 females or 200 males. They did not report egg production, but it seems likely that fully-fed females lay many eggs whereas females on restricted diets lay few (4). Even in all male containers, fully-fed males may have engaged in behavior associated with attracting females (such as courtship songs composed of wing vibrations) to a greater extent than males on restricted diets. Hence, Mair et al.'s findings could be due to a switch in and out of costly reproductive activity, but evidence for this will require further study.

Second, in rodent experiments, diets are restricted by reducing food quantity (generally to $60 \%$ or ad libitum), whereas in Drosophila experiments, the effect is achieved by reducing food quality. In their study, Mair et al. cut the yeast and sugar content of the fly diet to about $43 \%$ of that in standard laboratory medium. Other work in Mediterranean fruit flies (medflies) (5) shows that reductions in food quantity do not increase longevity (6), whereas reductions in food quality do (7). A key uncertainty is whether quantity- or quality-restricted diets or ad libitum diets mimic conditions in the wild. 
Mair et al.'s findings are important not only in the context of dietary-restriction research but also from the broader perspective of what determines longevity. Demographers have shown that age-specific death rates for humans are strongly influenced by current conditions and behaviors. Mortality, even at advanced ages, is highly plastic. This is well illustrated by the "natural experiment" of German unification, analogous to the laboratory experiments of Mair and colleagues.

Following unification of East and West Germany (1989-1990), mortality in the East declined toward prevailing levels in the West, especially among the elderly $(8,9)$ (see the figure). Although conditions early in life do significantly influence human health and survival late in life (10), the German example — and other demographic data—provide strong evidence that such effects are of less importance (at least in more recent decades) than changes in current conditions $(2,11,12)$. The second half of the 20th century saw a radical (and continuing) decline in old-age mortality in most developed countries: in Western Europe, for instance, from 1950 to 2000 the probability of surviving from age 80 to 100 increased 20-fold (13). Most of this increase is due to improvements in economic and social conditions and to ongoing medical advances (14).

Epidemiological and clinical research provide further evidence of the malleability of old age. For example, the risk of death for elderly smokers who quit falls, within 1 or 2 years, to a lower level than that suffered by recalcitrant smokers (15). There is a growing appreciation that even octogenarians and nonagenarians can substantially benefit from medical interventions such as cataract surgery (16) and hip replacement (17). Low-tech interventions at advanced ages can have an important impact. For instance, Fiatrone $e t$ al. found that physical training leads to significant gains in muscle strength, size, and functional mobility among frail residents of nursing homes: The oldest person studied (and helped) was 96 years old (18).

Aristotle contrasted premature death with natural death due to old age- - he asserted that nothing could be done about old age (19). More than 23 centuries later, many still believe that death rates at older ages are intractable (20). This view is reinforced by evolutionary theories of aging, which emphasize that senescence is inevitable because the force of selection against deleterious, late-acting mutations declines with age (21). Research over the past decade strongly supports an encouraging alternative- that aging is plastic and survival can be substantially extended by various genetic changes and nongenetic interventions (1-2,5,7-18, 20 ). For most species, damage to cells and tissues accumulates with age, and mortality rises. Nonetheless, aging is so remarkably pliable that interventions do not have to be lifelong. As illustrated by the Mair et al. report and other studies, interventions even late in life can switch death rates to a lower, healthier trajectory.

Are there any limits to the extraordinary malleability of aging? Will an article in Science soon report that various genetic changes and nongenetic interventions can help nematode worms, Drosophila, or medflies (which ordinarily live a few weeks at most) to survive more than a year? Since 1840 , record life expectancy has increased by $21 / 2$;years per decade (20). Will this march to longevity continue for many more decades? What genetic mechanisms and physiological processes determine the malleability of aging? Why does evolution license it? These are the kinds of questions that will spur future mortality research.

\section{References and Notes}

1. Mair W, Goymer P, Pletcher SD, Partridge L. Science 2003;301:1731. [PubMed: 14500985]

2. Vaupel JW, et al. Science 1998;280:855. [PubMed: 9599158]

3. Vaupel JW, Yashin AI. Am Stat 1985;393:176. [PubMed: 12267300]

4. Good TP, Tatar M. J Insect Physiol 2001;47:1467. [PubMed: 12770153] 
5. Carey, JR. Longevity: The Biology and Demography of Life Span. Princeton Univ. Press; Princeton, NJ: 2003.

6. Carey JR, et al. Aging Cell 2002;1:140. [PubMed: 12882344]

7. Carey JR, et al. Science 1998;281:996. [PubMed: 9703516]

8. Gjonca, A.; Brockmann, H.; Maier, H. Demogr Res. 2000. p. 1www.demographic-research.org

9. Scholz, R.; Maier, H. www.demogr.mpg.de/papers/working/wp-2003-031.pdf

10. Doblhammer, G. The Late Life Legacy of Very Early Life. www.demogr.mpg.de/papers/working/wp-2003-030.pdf

11. Kannisto, V. Development of Oldest-Old Mortality, 1950-1990. Odense Univ. Press; Odense, Denmark: 1994. www.demogr.mpg.de

12. Vaupel JW. Philos Trans R Soc London Ser B 1997;352:1799. [PubMed: 9460063]

13. Calculations based on data in the Human Mortality Database. www.mortality.orgVaupel, JW.; Jeune, B. Exceptional Longevity: From Prehistory to the Present. Jeune, B.; Vaupel, JW., editors. Odense Univ. Press; Odense, Denmark: 1995. p. 109-116.www.demogr.mpg.de

14. Riley, J. Rising Life Expectancy: A Global History. Cambridge Univ. Press; Cambridge: 2001.

15. LaCroix AZ, Omenn GS. Clin Geriatr Med 1992;8:69. [PubMed: 1576581]

16. Bergman B, Sjostrand J. Acta Ophthalmol Scand 2002;80:598. [PubMed: 12485279]

17. Pagnano MW, et al. Mayo Clin Proc 2003;78:285. [PubMed: 12630580]

18. Fiatarone MA, et al. J Am Med Assoc 1990;263:3029.

19. Aristotle. Ross, GRT., translator. On Youth and Old Age, On Life and Death, On Breathing. (350 BC.; http://classics.mit.edu/Aristotle/youth_old.html

20. Oeppen J, Vaupel JW. Science 2002;296:1029. [PubMed: 12004104]

21. Hamilton WD. J Theor Biol 1966;12:12. [PubMed: 6015424]

22. Supported in part by NIH grant AG-08761. R. Scholz, H. Maier, and S. Leek prepared the figure. 


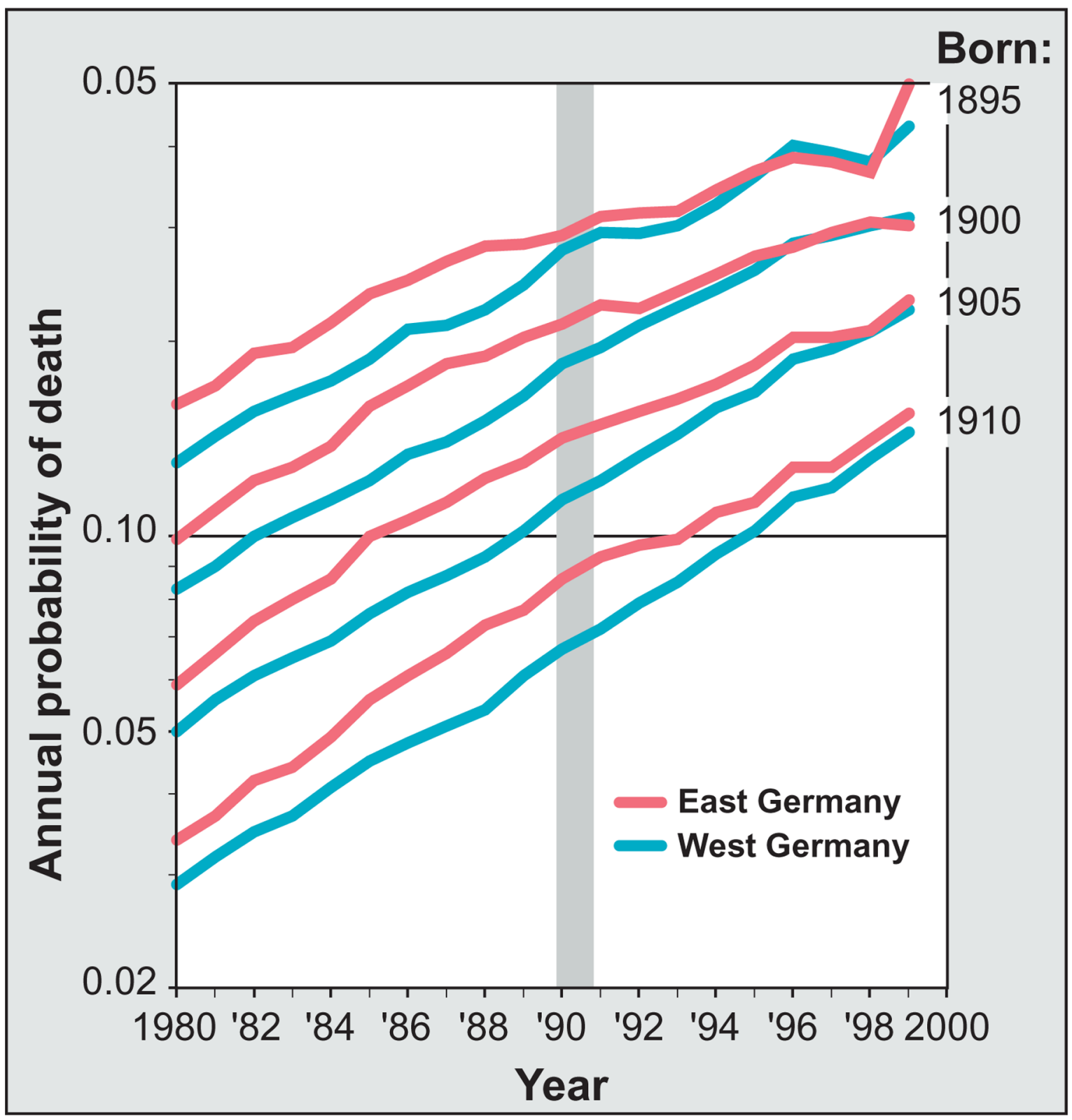

1. . East and West German death rates for cohorts born around 1900

The Berlin Wall fell on 9 November 1989 and formal unification of East and West Germany was completed on 3 October 1990 (gray column). Before 1989, the annual probability of death was considerably higher in East Germany compared with West Germany for cohorts born in $1895,1900,1905$, and 1910. In 1990, people born in these years were in their 80s and 90s.

Nonetheless, very old East Germans were able to benefit from medical, social, and economic improvements after unification. Consequently, their death rates converged toward those of West Germany. 